The University of San Francisco

USF Scholarship: a digital repository @ Gleeson Library |

Geschke Center

Sport Management

College of Arts and Sciences

3-30-2018

\title{
Reputation and the League Standing Effect: The Case of a Split Season in Minor League Baseball
}

Nola Agha

University of San Francisco, nagha@usfca.edu

Thomas Rhoads

Follow this and additional works at: https://repository.usfca.edu/sm

Part of the Sports Management Commons

\section{Recommended Citation}

Agha, Nola and Rhoads, Thomas, "Reputation and the League Standing Effect: The Case of a Split Season in Minor League Baseball" (2018). Sport Management. 23.

https://repository.usfca.edu/sm/23

This Article is brought to you for free and open access by the College of Arts and Sciences at USF Scholarship: a digital repository @ Gleeson Library | Geschke Center. It has been accepted for inclusion in Sport Management by an authorized administrator of USF Scholarship: a digital repository @ Gleeson Library | Geschke Center. For more information, please contact repository@usfca.edu. 


\title{
REPUTATION AND THE LEAGUE STANDING EFFECT: THE CASE OF A SPLIT SEASON IN MINOR LEAGUE BASEBALL
}

\begin{abstract}
Split season league design resets standings at the midpoint of the season, thus allowing for two periods in which a team can potentially achieve success in a single season. This context allows us to test both the reputation of the first half winner and the league standing effect on demand. Examination of game-level data from the 2010 Southern League reveals fans are unaffected by measures of both team quality and league standing in the second half of the season. On the other hand, the first half winners saw an $11 \%$ increase in attendance as a percent of stadium capacity, suggesting that in the second half of the season winners matter more than winning. (JEL L22 and L83)
\end{abstract}

Keywords: demand, minor league baseball, league standing effect, reputation, split season

Agha, N. \& Rhoads, T. A. (2018). Reputation and the league standing effect: The case of a split season in Minor League Baseball, Applied Economics, (50)41, 4447-4455.

https://doi.org/10.1080/00036846.2018.1456646 


\section{Introduction}

Consistently attracting fans to the ballpark is, of course, a primary goal of any professional baseball team. This strategy provides at least a few steady revenue streams, the most obvious being ticket, concession, and merchandise sales in addition to crowds that positively contribute to home field advantage and player development. For minor league baseball teams in particular, a business model that is more reliant on fans coming to the stadium is critical for success. Because other major sources of revenue that Major League Baseball teams can rely on—television revenue and revenue sharing, for instance-are mostly nonexistent for the minor leagues, there are sometimes alternative ways to create, enhance, and maintain fan demand for the ballpark experience. Additional entertainment such as postgame fireworks, concerts, and bobblehead giveaways are just a few of the more typical methods used to bring additional fans to the minor league ballpark that may not be drawn by the quality of the baseball competition alone. Much work has already focused on this aspect of minor league baseball attendance.

The literature shows that fans generally respond positively to team quality at all levels of professional sports. However, the response is somewhat muted for minor league sports-Gitter and Rhoads (2010) and Winfree and Fort (2008) found that average attendance increases only about $2 \%$ for minor league baseball and hockey teams when teams see a $10 \%$ increase in winning percentage. Focusing exclusively on minor league baseball, this result can be somewhat troubling from a revenue generation perspective for at least a few reasons. First, team quality is entirely a function of the Major League parent team. Minor league affiliates are meant to serve as the player development grounds for the Major League team while also providing opportunities to play in more distracting conditions in order to learn to focus and block out noise and heckling from fans. This suggests that winning games is not as important as developing player talent for 
the Major League team. Second, the minimal impact from the additional fans from winning suggests a team at the AA level of minor league baseball would see attendance increase by about 90 fans per game, or by about 6,250 fans annually. Using the minor league baseball average cost of about $\$ 65$ for a family of four to attend a game, this points to additional revenue of a little more than $\$ 1,400$ per game, or approximately $\$ 100,000$ per season that would be attributed to a higher quality team. ${ }^{1}$ While this figure is not insignificant, we must keep in mind that this additional revenue stream is purely a function of the quality of the minor league team, which is completely out of the control of the owners of that minor league team.

Given the above discussion, it should not be surprising that minor leagues cannot rely on winning alone to maintain or increase attendance. Promotions and special events are standard for minor league baseball—fireworks nights and bobblehead giveaways are typically the games with the highest attendance during the season. But another way some minor leagues appear to have tried to increase attendance is through a split season structure of regular season competition. In those minor leagues with a split season, the teams making the playoffs are determined by splitting the season into two halves to determine a first half and second half winner. The first half winner is determined as the team with the best record at the midpoint of the season. Then, at the midpoint of the season, the first half records are wiped clean and new second half standings are generated. The team with the best record in the second half of the season is the second half winner, and plays the first half winner in the playoffs. Usually, there are two divisions in a minor league with a split season and the winners of each half of these divisions meet in a playoff. All five leagues in the A level of minor league baseball use a split season format to determine playoff teams while neither of the two AAA level leagues do. The AA level of minor league

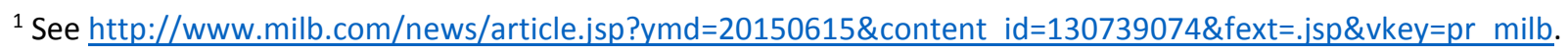
Accessed April 12, 2016.
} 
baseball is unique in that two of the three leagues - the Southern League and the Texas League_-both have a split season format, while the Eastern League does not. This unique nature of split season format at the AA level suggests leagues can attempt to optimize attendance through the playoff and season structure.

This paper examines the impact of a split season on game-level attendance in the Southern League for the 2010 season. We specifically focus on two possible reasons a split season approach to league and playoff design could affect attendance. First, the somewhat arbitrary resetting of the standings at the midpoint of the season means all teams are put in an equal position for playoff consideration at the start of the second half of the season, regardless of their performance in the first half of the season. Of course, the quality of the team is not likely to change much, if at all, at the midpoint of the season. So while the relative success, or lack of it, in the first half of the season is likely to carry over to the second half of the season, the reset standings may give the fan a new sense of how their team compares to the rest of the league. We test these ideas using Neale's (1964) league standing effect. Second, because the split season produces a first half winner in each of the two divisions in the Southern League, two teams are assured of making the end-of-the season playoffs. For these teams, this designation as a playoffquality team can therefore send a signal to their fans of team quality for the entire second half of the season. In other words, gaining a reputation as a playoff-caliber team may provide useful information to the fan of absolute team quality that may not be easily revealed or readily determined from the daily standings.

We get two primary results from our model. First, our results suggest Southern League fans are not responsive to the games behind metric used to test the league standing effect. Specifically, these fans are not sensitive to a daily indicator of team performance, relative team 
quality, and end-of-season championship possibilities. Further, this suggests more broadly that minor league baseball fans, unlike Major League Baseball fans, are mostly not concerned with the uncertainty of outcome. However, our model does provide a second result showing an 11point increase in per game attendance as a percent of capacity in the second half of the season for the first half winner that secured a spot in the postseason playoffs. These results together suggest that while minor league baseball fans do not appear to be sensitive to relative team performance, they do respond to a reputation signal of overall team quality.

The rest of this paper proceeds as follows. In the next section, we examine how the split season league and playoff design fits into the literature. In section three, we introduce the data and our model. Section four presents the results and in section five we discuss our results before concluding in the final section.

\section{Literature Review}

Developing a more complete understanding of how baseball fans respond to certain features of game, league and playoff design is perhaps the primary motivating factor for much of the research concerning minor league baseball. Baseball demand estimation began with Rottenberg (1956) and Noll (1974) and focused first on Major League Baseball before efforts were made to estimate minor league baseball demand. In moving to estimate demand for minor league baseball, Siegfried and Eisenberg (1980) opened opportunities for others to study things such as the impact of promotions (Gifis and Sommers 2006), winning (Gitter and Rhoads 2010), top prospects (Gitter and Rhoads 2011), stadium construction (Gitter and Rhoads 2014), parent club quality, distance, and affiliation changes (Agha and Cobbs 2015), proximity to other 
professional baseball teams (Rhoads 2015), team name changes (Agha, Goldman, and Dixon 2016), and a host of other factors (Anthony et al 2014).

The body of evidence documenting the impact on attendance at the minor league level is getting deeper and broader, and provides a further check on the robustness of the research examining demand at the major league level across sports. Minor league and major league live sporting events are typically viewed as substitutes by fans in baseball (Agha et al. 2016; Gitter and Rhoads 2010), hockey (Winfree and Fort 2008) and football (Fort and Quirk 1999), suggesting that minor league and major league sports fans can behave in a somewhat similar and predictable fashion. But there are some notable distinctions between minor league and major league sports. Agha (2013) identifies a positive impact on local income levels from minor league baseball teams not typically seen from Major League Baseball teams and Gitter and Rhoads (2010) and Agha and Cobbs (2015) find that fans respond minimally to winning minor league baseball teams in comparison to winning Major League Baseball teams. This suggests all professional sports leagues can potentially provide a reasonable arena within which to test economic theories, with some leagues possibly being better suited for testing than others.

We turn our focus now to Neale's (1964) league standing effect, which posits that "the closer the standings, and within any range of standings the more frequently the standings change, the larger will be the gate receipts" (p. 3). Importantly, it must be noted that it should be possible to apply and test the league standing effect in any professional sports league-including any minor league baseball league like the Southern League — that maintains and reports league standings and where there exists the potential for league standings or rank to change at any point before, during or after any game throughout the season (Andreff and Scelles 2015). In fact, a literature that emerged in the late 1980s and early 1990s began to focus more on the importance 
of the dynamics of championship league standings and the possible effects of daily changes on attendance instead of simply examining how end-of-season competitive balance was related to attendance. Cairns (1987) highlighted championship and relegation contention, especially in the second half of the season, in the Scottish Football League. Likewise, Borland (1987) controlled for those teams within two games of the league leader in the championship race in determining attendance in the Victorian Football League — an Australia Rules football league. While championship significance and league position were tested separately by Jennett (1984) for the Scottish Football League and by Dobson and Goddard (1992) for the English Football League, their metrics were ultimately found problematic by Baimbridge, Cameron and Dawson (1996) who studied championship and relegation significance in the English Premier League.

The problem with some of the previous models in controlling for championship significance is that fans were assumed to use information only available at the end of the season in order to make ex ante attendance decisions. Baimbridge, Cameron and Dawson (1996) work around this by including a dummy variable for a top four position in the standings, suggesting the team is in contention for the championship. Additionally, they included controls for whether or not the team already secured a championship or relegation for the following season. While none of these highlighted variables were found to be significant in describing match attendance, they nevertheless point to the types of variables that should be included when modeling the league standing effect in professional baseball. Specifically, baseball fans pay attention to the standings and the closeness of those standings through the games behind metric. This metric is reported on a daily basis and shows how many wins (games) behind the current first place team any given baseball team in the league is. The games behind metric is reported in the standings 
and is updated in the newspaper and on league websites after every game is completed and is readily available for any fan to access.

We note that some previous studies used the games behind metric to test the uncertainty of outcome hypothesis. The games behind metric provides information to baseball fans about the relative quality of the baseball teams playing, making it possible to form an ex ante prediction about the uncertainty of outcome. Knowles, Sherony and Haupert (1992) include the sum of the games behind for both the home and visiting teams playing the game while Soebbing (2008) includes just the games behind for the home team. While these two previous studies were certainly not the first to examine the impact of games behind on attendance (see, for example, Demmert 1973, Noll 1974, and Whitney 1988) they do highlight a very common technique used to test the uncertainty of outcome hypothesis. And while even more complex measures of game and league championship uncertainty and game importance exist, (see Tainsky and Winfree, 2010 and Lei and Humphreys 2013) they are not expected to be easily accessible or used readily by fans to make a decision about attending a baseball game.

We suggest here that the games behind metric is perhaps a better test of the league standing effect as it is likely the metric most commonly used by fans to assess both relative team quality and the likely significance of each game in the end-of-season championship race. Two recent papers explicitly test the league standing effect. In looking at Major League Baseball, Humphreys and Zhou (2015) use a measure that is probably less intuitive or accessible to fans than a games behind metric, while Andreff and Scelles (2015) use a metric for the French football league that is not as comprehensive in describing the championship possibilities as a standard games behind metric. These two papers provide mixed results of the presence of the league standing effect. 
We must emphasize that the Southern League's split season—and other leagues similarly structured—where league standings are reset at the midpoint of the season, appears to be designed in order to benefit from a fan's expected preference to attend a baseball game with a more direct and immediate impact on the end-of-season championship race. To our knowledge, split season minor league baseball has not been used as a test bed to examine the extent to which the league standing effect exists. In fact, Medcalfe (2009) seems to be the only one to have used split season minor league data in any work, but he examined team effort and not fan demand resulting from the league standing effect. Thus, our research is expected to fill a gap in the literature by testing the league standing effect by using split season data from the Southern League of AA minor league baseball. Finally, we will additionally test the reputational effects afforded to the first half winner in attracting fans to the ballpark. This feature of league design has attracted little attention as it relates to fan demand, but reputation due to winning the season's first half is expected to provide critical information to the fan regarding relative team quality and end-of-season championship possibilities (see Czarnitzki and Stadtmann 2002 and Ertug and Castellucci 2013).

\section{Data and Model}

Demand for a professional sporting event is necessarily a function of the league standing effect in addition to team and game quality. Neale's (1964) observation that "progress towards a championship or changes in the standings" can help determine demand for a sporting event and suggests that in order to incorporate a split season league design, a demand model must allow for the possibility of two halves in a season and the opportunity to identify the first half division winners. Our demand model for split season minor league baseball below is unique in that it 
includes split season flexibility in identifying the league standing effect for each half of the season in addition to the standard inclusion of team and game quality measures that drive game attendance:

Game Attendance $=\mathrm{F}\left(1^{\text {st }}\right.$ Half League Standing Effect, $2^{\text {nd }}$ Half League Standing Effect, $1^{\text {st }}$ Half Division Winner, Team Quality, Game Quality)

To test the league standing effect and the reputational effect of a split season first half winner, we used individual home game observations from all 10 teams in the 2010 Southern League season $(n=693)$. Specifically, we utilized ordinary least squares (OLS) to estimate

$$
y_{i j}=\beta_{1} X_{i j}+\beta_{2} Z_{i j}+v_{i}+\varepsilon_{i j}
$$

where $\mathrm{y}_{\mathrm{i}}$ is per game attendance as a percent of stadium capacity for team $i$ in game $j$, similar to Cebula, Toma, and Carmichael (2009). $\mathrm{X}_{\mathrm{ij}}$ captures team quality and game quality, $\mathrm{Z}_{\mathrm{ij}}$ contains split season-related indicators, $v_{\mathrm{i}}$ are city fixed-effects, and $\varepsilon_{\mathrm{ij}}$ is a random disturbance. If the split season format successfully results in two separate "seasons" then each half should be analyzed separately thus we also estimate this model by removing $Z_{i}$ from equation (1) and replacing it with a single indicator for the first half winner. We relied on the plentiful research on individual game demand in minor league baseball to formulate our empirical specification (Anthony et al. 2014; Cebula et al. 2009; Howell, Klenosky, and McEvoy 2015; Paul, Toma, and Weinbach 2009; Paul and Weinbach 2013a; Paul and Weinbach 2013b; Siegfried and Eisenberg 1980) where individual game demand is a function of team quality, game quality, and city-specific features.

Team quality is captured through win percent, cumulative homeruns, and the number of top prospects defined as any player ranked in the top 20 by Baseball America at the start of the 2010 season. Both win percent and cumulative homeruns are calculated for each game and are 
re-set at the beginning of the second half due to the split season. We expect the coefficients on both the number of top prospects (Gitter and Rhoads 2011) and the number of homeruns (Gitter and Rhoads 2010; Siegfried \& Eisenberg 1980) to be positive. Both Agha and Cobbs (2015) and Gitter and Rhoads (2010) found the coefficient on win percent to be positive and significant in AA leagues as a whole, but analysis of only the Southern League (Anthony et al. 2014; Paul and Weinbach 2013a) found the coefficient on win percent to be insignificant. Game quality is captured by dummy variables for opening day, doubleheader, day of the week, month, weather, fireworks, and non-fireworks promotions. City fixed effects are included to capture constants such as population, per capita income, preference for minor league baseball, and other unobservable city specific features.

Relying on Neale's (1964) claim that gate receipts derive from, "excitement in the daily changes in the standings or...possibilities of changes in standings" (p. 3) we operationalize the league standing effect as games behind. This common measure is widely distributed, easily understood by local fans, and can signal both potential excitement for a game, and "progress towards a championship" (Neale, 1964, p. 4). In a split season this progress occurs twice-once halfway through the season and once at the end. Thus, games behind is re-set halfway through the season. To be thorough, we test both games behind for the home team (Soebbing 2008) and the sum of games behind for both home and visiting teams (Knowles et al. 1992). Furthermore, we test for a possible reputational effect of the first half winner on second half demand with a dummy variable. Table 1 summarizes the descriptive statistics for each of the variables.

To date, all demand modeling on minor league baseball has omitted measurement of a split season league and analyzed a single season as if it had one championship. Thus we begin with a single equation that captures team quality, game quality, and city-specific features. To 
capture the unique structure of the split season league we include an indicator for first half games, an interaction of this first half dummy and games behind, and an indicator for the first half winners, of which there are two (one for each division). The full season empirical specification is AttendanceAsPctOfCapacity $=\beta_{0}+\beta_{1}$ FirstHalfWinner $+\beta_{2}$ FirstHalfDummy + $\beta_{3}$ FirstHalfWinnerxFirstHalfDummy $+\beta_{4}$ TopProspects $+\beta_{5}$ WinPct $+\beta_{6}$ Homeruns + $\beta_{7}$ GamesBehind $+\beta_{8}$ OpeningDay $+\beta_{9}$ Doubleheader $+\beta_{10-15}$ DayOfWeek $+\beta_{16-20}$ Month + $\beta_{21}$ Temperature $+\beta_{22}$ Windspeed $+\beta_{23}$ Clear $+\beta_{24}$ Sunny $+\beta_{25}$ Cloudy $+\beta_{26}$ Overcast $+\beta_{27}$ Drizzle $+\beta_{28}$ Rain $+\beta_{29}$ Fireworks $+\beta_{30}$ NonFireworksPromotion + city fixed-effects $+\varepsilon$

The empirical specification for separate first and second halves removed the first half dummy and the interaction term and months were adjusted accordingly.

\section{Results}

We used OLS to estimate both the full and half season models. A Breusch-Pagan / CookWeisberg test for heteroskedasticity indicated the need for robust standard errors in the full season $\left(\chi^{2}=36.39, \mathrm{p}<0.001\right)$, first half $\left(\chi^{2}=13.93, \mathrm{p}<0.001\right)$, and second half $\left(\chi^{2}=32.17, \mathrm{p}=\right.$ 0.08 ) regressions. Variance inflation factors under 10 indicate multicollinearity is not a problem in the first half and second half regressions.

To determine whether the data should be pooled into full season or regressed by halves of the season, we tested for the equality of coefficients with a Hausman test using seemingly unrelated regressions. The results indicate we can reject the equality of the common coefficients between the full season and first half $\left(\chi^{2}=87.25, \mathrm{p}<0.0001\right)$ and between the full season and the second half $\left(\chi^{2}=104.34, \mathrm{p}<0.0001\right)$. 
Overall, our results in Table 2 are consistent with previous research on per game attendance. As expected, we find attendance as a percent of capacity increases with promotions, good weather, opening day, and Thursday, Friday, and Saturday games. Additionally, rain tends to decrease attendance as a percent of capacity. Coefficients on team quality, measured as top prospects and homeruns, were insignificant and line up with other estimations of demand for Southern League baseball (Anthony et al. 2014; Paul and Weinbach 2013a). On the other hand, team quality measured as win percent was significant in the first half but not the second half or full season models. Table 2 further indicates the coefficient on the home team games behind metric is insignificant in all cases, and a separate analysis found the coefficient on the sum of games behind for the home and away teams was similarly insignificant $(\mathrm{p}>0.4)$ with no change in any of the other variable estimates. ${ }^{2}$ Finally, first half winners are associated with an 11-point gain in attendance as a percent of stadium capacity in the second half of the season.

\section{Discussion}

Neale's (1964) league standing effect proposes that close standings, actual changes in standings, or the possibility of changes in standings generate excitement in fans who then convert that excitement into gate revenues. In theory, the split season league design attempts to maximize this benefit for minor league baseball teams by providing more than just the usual one period for a team to achieve success in the regular season. By providing a chance for a team to either be the first half or second half winner during two distinct periods of the regular season, league standings have more opportunity to be close and potentially matter more. Our results

\footnotetext{
2 These results are available upon request.
} 
indicate that fans of AA Southern League baseball are not motivated to attend games due to any measure of league standing in either half of the season. In fact, team win percent is the only measure of team quality that affects demand in the first half of the season. When the second half of the season begins, winning ceases to matter altogether. Instead, the first half winner benefits from its reputation as a winner-attendance as a percent of stadium capacity increases $11 \%$ in the second half of the season for the first half winner. These results are consistent with Czarnitzki and Stadtmann (2002) who similarly found significant reputational effects that outweighed measures of league position and Rindova et al (2005) who found prominence can be more powerful than the ability to produce quality output. In short, in the split season minor league baseball context, gaining a reputation as a winner becomes more important than actually winning.

If fans are generally uninterested in the sporting performance of a minor league team focused on developing player talent, Neale's Fourth Estate Benefit might explain why first half winners see an 11 point increase in attendance in the second half of the season. He suggests the "reporter-newspaper-printer-distributor complex" (Neale 1964, p. 3) is incentivized to tout the success of the first half winner. A minor league baseball team that is the first half winner and has an active marketing department thus appears to have a strong incentive to directly promote the quality of their playoff-caliber team. This not only drives revenue to the firm, but can also meaningfully signal to the fans that a team has a reputation as a winner.

Bounded rationality provides an alternate explanation to the notion that fans respond to first half winners but not to winning. While fans could benefit from using the games behind metric in making a decision of whether or not to attend a baseball game, the cost of making that decision may simply be too high. The level of information about the quality of the team provided from 
being credentialed as a first half winner is likely enough to offset any cost of acquiring that information. Southern League baseball fans thus appear to exhibit bounded rationality in their decisions to attend baseball games.

Reputation as a playoff-caliber team thus seems to matter for fans in this setting where information acquisition is costly and can lead directly to an additional revenue stream for the first half winner. An increase in attendance of $11.4 \%$ of stadium capacity leads to an additional 884 fans per game for the average Southern League team. With the average AA baseball ticket price around $\$ 7.00$, this suggests the first half winner in the Southern League can increase ticket revenue in the second half of the season by more than $\$ 200,000$. Concessions and ancillary purchases at the stadium can be expected to add to the bump in revenue the first half winner could receive.

These results have interesting implications for demand modeling. First, they indicate that leagues utilizing a split season design have unique demand characteristics by half and should be estimated as such. This will be a challenge to future researchers when analyzing classifications like AA that have both a split and non-split season format among the different leagues. Second, while full season analysis finds significant effects of win percent in AA leagues (Agha and Cobbs 2015; Gitter and Rhoads 2010) game-level analysis does not. This difference could stem from the split season first half winner driving some of the results or from the differences between split season and non-split season leagues.

The results of our research also have implications beyond baseball in some settings where reputation as a winner matters and information acquisition is not costless. An Academy Award nomination, for example, provides a strong reputational signal about a film's quality to a potential consumer. Box-office revenues increase with nominations (Nelson et al 2001), 
suggesting that movie release dates can be a function of award schedules. But our results further suggest that more awards in the entertainment industry may provide more opportunities for films and television shows to gain a reputation for high quality. This allows consumers to gain information about the quality of a movie or television show with relatively low acquisition costs and can lead to higher revenues for production studios as more consumers watch films and television shows considered the best. Also, consider the U.S. political landscape and the statelevel presidential primary contests that occur every four years. Primary candidates place a lot of emphasis on winning the early races—New Hampshire, Iowa, and South Carolina, for instancewith the expectation that an early win can provide momentum for future primary contests in other states. An early win can send a signal to a future voter in another state about quality of the candidate in a way that suggests reputation as a winner matters to voters much like reputation as a playoff-caliber team matters to Southern League baseball fans.

Although a split season design allows standings to reset at the midpoint of the season, the reality is that team quality changes little, if at all, at this point. That observation, coupled with our results, nevertheless raises important questions about league design. For example, what would happen to Southern League attendance if there was no split season or what would happen to the Eastern League (currently no split season) if a split season was implemented? Similarly, would MLB benefit from a split season? We encourage future researchers to examine more years and more leagues to determine the robustness of our results. Finally, future research should also attempt to more accurately determine those quality metrics that matter to minor league baseball fans.

\section{Conclusion}


The minor league baseball business model centers on drawing fans to the ballpark primarily with savvy marketing and promotions. In alignment with many minor league baseball executives who claim the business is about "family entertainment" (Johnson 1995; Pietschmann 2010), the results of this analysis indicate the quality of the team and the closeness of the championship race — that is, the league standing effect—generally do not motivate fans of Southern League baseball to attend games. This holds true despite a split season league design that doubles the opportunities for fans to see their team achieve success. In contrast, winning the first half is comparable to having a fireworks night every night for the second half of the season-a truly meaningful result for minor league managers and marketers.

Acknowledgements

The authors wish to thank Jeff Gurney for sharing his Southern League data. 


\section{References}

Agha, N. (2013). The economic impact of stadiums and teams: The case of Minor League Baseball. Journal of Sports Economics, 14(3), 227-252.

Agha, N., \& Cobbs, J. (2015). Is the grass greener? Switching costs and geographic proximity in the high status affiliations of professional baseball. Managerial and Decision Economics, DOI: 10.1002/mde.2741

Agha, N., Goldman, M., \& Dixon, J. C. (2016). Rebranding: The value of team name changes, European Sport Management Quarterly, 16(5), 673-693.

Andreff, W., \& Scelles, N. (2015). Walter C. Neale 50 years after: Beyond competitive balance, the league standing effect tested with French football data. Journal of Sports Economics, 16(8), 819-834.

Anthony, T., Kahn, T., Madison, B., Paul, R. J., \& Weinbach, A. (2014). Similarities in fan preferences for minor league baseball across the American southeast. Journal of Economics and Finance, 38(1), 150-163.

Baimbridge, M., Cameron, S. \& Dawson, P. (1996). Satellite television and the demand for football: A whole new ball game? Scottish Journal of Political Economy, 43(3), 317.

Borland, J. (1987). The demand for Australian Rules Football. Economic Record, 63(182), 220.

Cairns, J. A. (1987). Evaluating changes in league structure. The reorganization of the Scottish Football League. Applied Economics, 19(2), 259-275.

Cebula, R. J., Toma, M., \& Carmichael, J. (2009). Attendance and promotions in minor league baseball: The Carolina League. Applied Economics, 41(25), 3209-3214.

Czarnitzki, D., \& Stadtmann, G. (2002). Uncertainty of outcome versus reputation: Empirical evidence for the First German Football Division. Empirical Economics, 27(1), 101-112.

Demmert, H. G. (1973). The economics of professional team sports: Lexington, Mass., Lexington Books [1973].

Dobson, S. M., \& Goddard, J. A. (1992). The demand for standing and seated viewing accommodation in the English Football League. Applied Economics, 24(10), 1155.

Ertug, G., \& Castellucci, F. (2013). Getting what you need: How reputation and status affect team performance, hiring, and salaries in the NBA. Academy of Management Journal, 56(2), 407-431. 
Fort, R \& Quirk, J. (1999). The college football industry. In Fizel, J., Gustafson, E., \& Hadley, L. (Eds.). Sports economics: Current research: Westport, CT: Praeger.

Gifis, L. S., \& Sommers, P. M. (2006). Promotions and attendance in Minor League Baseball. Atlantic Economic Journal, 34(4), 513-514.

Gitter, S. R., \& Rhoads, T. A. (2010). Determinants of Minor League Baseball attendance. Journal of Sports Economics, 11(6), 614-628.

Gitter, S. R., \& Rhoads, T. A. (2011). Top prospects and Minor League Baseball attendance. Journal of Sports Economics, 12(3), 341-351.

Gitter, S. R., \& Rhoads, T. A. (2014). Stadium construction and Minor League Baseball attendance. Contemporary Economic Policy, 32(1), 144-154.

Howell, S. M., Klenosky, D. B., \& McEvoy, C. D. (2015). Weather, timing, and promotions in Minor League Baseball: An examination of attendance in the International League. Journal of Applied Sport Management, 7(2).

Humphreys, B. R., \& Zhou, L. (2015). The Louis-Schmelling Paradox and the league standing effect reconsidered. Journal of Sports Economics, 16(8), 835-852.

Jennett, N. I. (1984). Attendances, uncertainty of outcome and policy in Scottish League Football. Scottish Journal of Political Economy, 31(2), 176-198.

Johnson, A. T. (1995). Minor league baseball and local economic development. Urbana and Chicago: University of Illinois Press.

Knowles, G., Sherony, K., \& Haupert, M. (1992). The demand for Major League Baseball: A test of the uncertainty of outcome hypothesis. American Economist, 36(2), 72-80.

Lei, X. \& Humphreys, B. (2013). Game importance as a dimension of uncertainty of outcome. Journal of Quantitative Analysis in Sports, 9(1), 25-36.

Medcalfe, S. (2009). Incentives and league structure in Minor League Baseball. Journal of Sport Management, 23, 119-141.

Neale, W. C. (1964). The peculiar economics of professional sports: a contribution to the theory of the firm in sporting competition and in market competition. Quarterly Journal of Economics, 78, 1-14.

Nelson, R., Donihue, M., Waldman, D., \& Wheaton, C. (2001). What's an Oscar Worth? Economic Inquiry, 39, 1-16.

Noll, R. G. (1974). Attendance and price setting. In R. G. Noll (Ed.), Government and the sports business (pp. 115-157). Washington, DC: Brookings Institution. 
Paul, R. J., Toma, M., \& Weinbach, A. P. (2008). The minor league experience: What drives attendance at South Atlantic League baseball games? Coastal Business Journal, 8(1), 70-84.

Paul, R. J., \& Weinbach, A. P. (2013a). Fireworks saturation and attendance in minor league baseball. International Journal of Sport Finance, 8(4), 312.

Paul, R. J., \& Weinbach, A. P. (2013b). The Yankee effect in Minor League Baseball. New York Economic Review, 44(1), 32-42.

Pietschmann, R. J. (2010, March 30). Diamond Mines. Departures, Retrieved from http://www.departures.com/lifestyle/consuming-passions/diamond-mines

Rhoads, T. (2015). The call up to the majors: A proximity-based approach to the economics of Minor League Baseball. New York, NY: Springer.

Rindova, V. P., Williamson, I. O., Petkova, A. P., \& Sever, J. M. (2005). Being good or being known: An empirical examination of the dimensions, antecedents, and consequences of organizational reputation. Academy of Management Journal, 48(6), 1033-1049.

Rottenberg, S. (1956). The baseball players' labor market. Journal of Political Economy, 64, 242-258.

Siegfried, J. J., \& Eisenberg, J. D. (1980). The demand for Minor League Baseball. Atlantic Economic Journal, 8(2), 59-69.

Soebbing, B. P. (2008). Competitive balance and attendance in Major League Baseball: An empirical test of the uncertainty of outcome hypothesis. International Journal of Sport Finance, 3(2), 119-126.

Tainsky, S., \& Winfree, J. A. (2010). Short-run demand and uncertainty of outcome in Major League Baseball. Review of Industrial Organization, 37(3), 197-214.

Whitney, J. D. (1988). Winning games versus winning championships: The economics of fan interest and team performance. Economic Inquiry, 26(4), 703-724.

Winfree, J. A., \& Fort, R. (2008). Fan substitution and the 2004-05 NHL lockout. Journal of Sports Economics, 9(4), 425-434. 
Table 1. Descriptive statistics of 2010 Southern League home games

\begin{tabular}{|c|c|c|c|c|}
\hline Variable & Mean & Std. Dev. & Min & Max \\
\hline \multicolumn{5}{|l|}{ Dependent variable } \\
\hline Attendance as a percent of capacity & 0.445 & 0.252 & .043 & 1.332 \\
\hline \multicolumn{5}{|l|}{ Split Season Measures } \\
\hline First half winner dummy & 0.101 & 0.302 & 0 & 1 \\
\hline First half dummy & 0.498 & 0.500 & 0 & 1 \\
\hline Games behind by half $x$ First half dummy & 2.081 & 3.484 & 0 & 16.5 \\
\hline \multicolumn{5}{|l|}{ Team Quality } \\
\hline Number of top prospects & 0.127 & 0.333 & 0 & 1 \\
\hline Win percent by half & 0.496 & 0.142 & 0 & 1 \\
\hline Cumulative homeruns by half & 10.909 & 7.912 & 0 & 37.0 \\
\hline \multicolumn{5}{|l|}{ Game Quality } \\
\hline Games behind, home team, by half & 3.958 & 3.904 & 0 & 16.5 \\
\hline Games behind, sum of both teams, by half & 7.851 & 5.717 & 0 & 23.5 \\
\hline Opening day dummy & 0.014 & 0.119 & 0 & 1 \\
\hline Doubleheader & 0.091 & 0.288 & 0 & 1 \\
\hline Sunday & 0.141 & 0.349 & 0 & 1 \\
\hline Tuesday & 0.104 & 0.305 & 0 & 1 \\
\hline Wednesday & 0.143 & 0.350 & 0 & 1 \\
\hline Thursday & 0.162 & 0.368 & 0 & 1 \\
\hline Friday & 0.154 & 0.362 & 0 & 1 \\
\hline Saturday & 0.157 & 0.364 & 0 & 1 \\
\hline April & 0.159 & 0.366 & 0 & 1 \\
\hline May & 0.203 & 0.403 & 0 & 1 \\
\hline July & 0.189 & 0.392 & 0 & 1 \\
\hline August & 0.206 & 0.405 & 0 & 1 \\
\hline September & 0.045 & 0.207 & 0 & 1 \\
\hline Temperature & 84.156 & 8.567 & 54 & 104 \\
\hline Wind speed & 6.929 & 4.303 & 1 & 26 \\
\hline Clear & 0.253 & 0.435 & 0 & 1 \\
\hline Sunny & 0.059 & 0.236 & 0 & 1 \\
\hline Cloudy & 0.175 & 0.380 & 0 & 1 \\
\hline Overcast & 0.066 & 0.249 & 0 & 1 \\
\hline Drizzle & 0.009 & 0.093 & 0 & 1 \\
\hline Rain & 0.017 & 0.131 & 0 & 1 \\
\hline Fireworks & 0.182 & 0.386 & 0 & 1 \\
\hline Non-fireworks promotions & 0.691 & 0.462 & 0 & 1 \\
\hline
\end{tabular}


Table 2. Demand estimation on attendance as a percent of capacity in the Southern League, 2010

\begin{tabular}{|c|c|c|c|}
\hline & $\begin{array}{c}\text { Full Season } \\
\quad \beta \\
\end{array}$ & $\begin{array}{c}\text { First Half } \\
\beta \\
\end{array}$ & $\begin{array}{c}\text { Second Half } \\
\beta \\
\end{array}$ \\
\hline First half winner dummy & 0.0552 & & $0.1144 *$ \\
\hline First half dummy & -0.0259 & & \\
\hline $\begin{array}{l}\text { Games behind by half } x \text { First } \\
\text { half dummy }\end{array}$ & -0.0018 & & \\
\hline Number of top prospects & -0.0008 & -0.0774 & -0.0169 \\
\hline $\begin{array}{l}\text { Win percent by half } \\
\text { Cumulative homeruns by }\end{array}$ & 0.0188 & $0.1708^{*}$ & -0.1237 \\
\hline half & 0.0026 & 0.0030 & -0.0024 \\
\hline $\begin{array}{l}\text { Games behind, home team, } \\
\text { by half }\end{array}$ & 0.0011 & -0.0013 & -0.0001 \\
\hline Opening day dummy & 0.1843 & 0.1312 & 0.0000 \\
\hline Doubleheader & -0.0276 & -0.0362 & -0.0193 \\
\hline Sunday & 0.0190 & -0.0296 & 0.0561 \\
\hline Tuesday & 0.0192 & 0.0556 & -0.0153 \\
\hline Wednesday & 0.0372 & $0.0902 *$ & -0.0186 \\
\hline Thursday & $0.0665 * *$ & $0.0763^{*}$ & $0.0551^{*}$ \\
\hline Friday & $0.1898 * * *$ & $0.2265 * * *$ & $0.1642 * * *$ \\
\hline Saturday & $0.2515^{* * *}$ & $0.2932 * * *$ & $0.2213 * * *$ \\
\hline April & 0.0682 & $0.1084 *$ & \\
\hline May & $0.0479 *$ & $0.0647 *$ & \\
\hline July & 0.0297 & & 0.0532 \\
\hline August & -0.0554 & & 0.0205 \\
\hline September & -0.0606 & & 0.0465 \\
\hline Temperature & 0.0001 & 0.0011 & 0.0014 \\
\hline Wind speed & -0.0009 & -0.0018 & 0.0018 \\
\hline Clear & 0.0157 & -0.0176 & $0.0450^{*}$ \\
\hline Sunny & $0.0719^{*}$ & $0.0979 *$ & 0.0514 \\
\hline Cloudy & $-.0392 *$ & -0.0420 & -0.0184 \\
\hline Overcast & -0.0228 & -0.0322 & 0.0199 \\
\hline Drizzle & -0.0468 & $-0.1660 * * *$ & -0.0560 \\
\hline Rain & $-0.1344 * * *$ & $-0.2109 * * *$ & $-0.1126^{*}$ \\
\hline Fireworks & $0.1447 * * *$ & $0.1119 * * *$ & $0.1629 * * *$ \\
\hline Non-fireworks promotions & $0.0671 * * *$ & $0.1244 * * *$ & 0.0275 \\
\hline Observations & 683 & 340 & 343 \\
\hline $\mathrm{R}^{2}$ & 0.6288 & 0.6202 & 0.7230 \\
\hline
\end{tabular}

